\title{
The lasting trauma of the concentration camps
}

\author{
The children and grandchildren of survivors may also be affected
}

We have known for centuries that traumatic events, physical or mental, have a profound and often lasting effect on the personality. Yet somehow we keep forgetting this phenomenon: it has been rediscovered, redescribed, and renamed by each generation.

War reminds us forcibly of the facts. In the past 100 years, the immediate impact of battle on the individual has been described variously as soldier's heart, effort syndrome, and irritable heart (dating from before 1900); from the first world war came shell shock, commotional and emotional shock, and the longer term picture, described as war neurosis and traumatic neurosis; still later, from the second world war, came the survivor syndrome and the concentration camp syndrome.

The Korean and Vietnam wars produced formal descriptive classifications of the sequelae of exposure to violent stressors in the Diagnostic and Statistical Manual of Mental Disorders, First Edition (DSM-I) and DSM-III, but the category was omitted in DSM-II, which was written when there was no war.' Currently, under the heading of post-traumatic stress disorder, the symptoms that characterise these variously named states-acute and chronic anxiety, depression, restlessness, irritability, sleeplessness, nightmares, and withdrawal from family and friends-are recognised as familiar sequelae not only of war but also of a host of more or less public events, whether accidental or intentional. These include physical and sexual abuse, rape, kidnapping, hostage taking, brainwashing, crashes, and fires.

By now it may be part of common wisdom that horrific events disrupt the personality, but that knowledge somehow lives disconnectedly side by side with the belief that people "get over" such events quickly, especially if provided with a rest, a holiday in the sun, or a large cheque.

One long term consequence of trauma is a greatly increased vigilance: although apparently behaving normally, people once caught in, for example, a large fire, can be forever checking out the electric wiring and the position of emergency exits. The disastrous event continues to exist actively in the mind, although it can be more or less well encapsulated or hidden. Survivors may avoid situations that they fear can break into that no go area, through sights, sounds, smells, or certain words, so that life can become increasingly restricted. Moreover, we have an inbuilt drive to understand, to make sense of our own experience, perhaps especially the apparently arbitrary. Thus we link the traumatic event with what is already familiar, or similar. Not surprisingly, disasters in the present often unearth troubles from the past which have been more or less managed until that point. In this way the trauma can acquire a loading of past meaning which may contribute to its corrosive effect. ${ }^{2}$

The legacy of the concentration camps was particularly devastating. ${ }^{3}$ The effects have persisted in the lives of children and grandchildren. What causes these far reaching consequences? A fundamental tenet of psychoanalytic theory is that at a deep level we construe all experience in terms of some notion of an agent, modelled on a parental figure, felt to be connected with that experience in a causal way, for good or ill. (Even naming an apparently arbitrary event "an act of God" is to acknowledge this.) The extremes of horror in the camps involved a systematic perversion, mutilation, and destruction of trust, first in the external world but rapidly extending inwards to the goodness of these internalised parental figures.

Experiences in the camps provoked hostility and guilt as well as pain and terror. Thus what gets destroyed is belief in the very possibility of good, within self as well as others. Some camp survivors spend the rest of their lives attempting to repair this damage, both internally and in the world-as did Primo Levi and Bruno Bettelheim through their writings and work. The causes of their suicides must be uncertain, but physical deterioration, old age, and the imminence of death bring an increasing helplessness-always difficult, but perhaps unbearable for those who feel death to be the final triumph of the bad. Suicide may be felt to be the only way left of defying, even destroying, the enemy.

What of the second and third generations? Work has shown that the children of parents who have carried within them, however silently, the experience of a destroyed world have much to contend with in growing up. Ordinary adolescent aggression can be seen by the parents as a return of the oppressor, making normal separation and individuation difficult. Survivors' children can have an 'intense need to act as redeemers for their parents"; many enter the helping professions. ${ }^{4}$

For those most deeply affected by trauma one of two long term outcomes is likely: melancholia, or a deep identification with the dead or damaged, ${ }^{5}$ which may enable the survivor to avoid the guilt that so often follows getting on with being alive; or, alternatively, an identification with the aggressors. ${ }^{6}$ The study of these phenomena, including childhood trauma, can throw light on the environmental factors that contribute to eventual personality and emotional disorders. ${ }^{7}$ These are complex matters, and there is much to be understood. In the 
meantime we must remember that the outcome of trauma is lasting. Forgetting something we wish was not true is only too easy.

CAROLINE GARLAND

Psychoanalyst

Tavistock Clinic,

London NW3 5BA
1 Choy T, de Bosset F Post-traumatic stress disorder: an overview Can f Psychiatr. 1992;37:578-83. Garland C. External trauma and the internal world: an approach to understanding survivors. In: Holmes J, ed. Textbook of Psychotherapy in Psychiatric Practice London: Churchill Livingstone, 991:507-32

3 Krystal H, ed. Massive psychic trauma New York: International University Press, 1968

4 Jucovy ME. Psychoanalytic contributions to holocaust studies. In $\mathcal{Y}$ Psychoanal 1992;73:267-82

5 Freud S. Mourning and Melancholia. Standard edition. Vol 14. London: Hogarth Press, 1915.

6 Lewis DO. From abuse to violence: psychophysiological consequences of maltreatment. $9 \mathrm{Am} \mathrm{Acad}$ Child Adolesc Psychiatry 1992;31:383-91.

\title{
The health of the nation's research and development
}

\author{
Time for some action
}

The Health of the Nation singled out five areas for special attention and set out a method to ensure that applied research would lead directly to better health in each of them. ${ }^{\prime}$ Another document, Research for Health, was launched last week by the secretary of state for health. ${ }^{2}{ }^{3}$ It summarises the progress and charts the direction of the Department of Health's strategy for research and development. This "places collective responsibility on the research community" and requires "a more robust and productive relationship between health problems and scientific investigation." It considers that "the imbalance between investigator-led research and problem-led research has resulted in insufficient attention being paid to a wide range of issues germane to health sector demands." This is only too true, but the problem does not lie with the clinical research community, many members of which have been trying for years to gain funding and academic recognition for projects that we would now call research and development.

Interestingly, in the same week that Research for Health was published the first project funded by the Department of Health's research and development programme has appeared in print. The Health Survey for England 1991 is a report by the Social Survey Division of the Office of Population Censuses and Surveys. ${ }^{+}$Although this report is obviously important for its content, it will also be read to see what light it sheds on the Department of Health's attitude to the spending of funds for research and development.

Concerned solely with cardiovascular disease, the survey describes a cross sectional sample of 3242 men and women aged over 16 in England who were studied in 1991 by questionnaire, examination, and blood sampling. The document provides details of height and indices of obesity and shows, for example, that, compared with the dietary survey of $1986-7,{ }^{5}$ the proportion of men who are obese (that is, have a body mass index $>30 \mathrm{~kg} / \mathrm{m}^{2}$ ) has increased from $7 \%$ to $13 \%$; the proportion of obese women has increased from $12 \%$ to $15 \%$.

The national mean blood pressure in men was $140 / 78$ $\mathrm{mm} \mathrm{Hg}$, and the report provides unsurprising data such as those showing a rise in pressure with age and an association with alcohol consumption. The survey found that about $70 \%$ of men and women had total blood cholesterol concentrations above the "desirable" figure of $5.2 \mathrm{mmol} / \mathrm{l}$. As for smoking habit, $30 \%$ of men and women were currently cigarette smokers, with $13 \%$ of men and $10 \%$ of women smoking more than 20 cigarettes a day. And so on through alcohol consumption, physical activity, and self reported general health and prevalence of cardiovascular disease.

The information on weight augurs ill for the Department of Health's target A.7, which is to reduce the proportion of the population who are obese by a quarter over the next decade. ${ }^{5}$ On the other hand, target A.6 is to reduce the mean systolic blood pressure in the adult population by at least $5 \mathrm{~mm} \mathrm{Hg}$ by the year 2005, and this may now be seen to be unnecessarily enthusiastic. Although the Health Survey for England emphasises the importance of knowing about baselines before setting targets, it does not help us to decide what sensible targets are. Nor do baseline data, however detailed and sophisticated, take into account the fact that with increasing knowledge targets change-for example, even the Americans are beginning to believe that "we should draw back from universal screening and treatment of blood cholesterol."'

The Health Survey of England will therefore be seen-at least as it stands - to be a somewhat pedestrian document. Its importance will undoubtedly increase as the survey is repeated and the number of subjects is increased (to 17000 this year). The most interesting results from this first survey, however, are the comparisons with earlier data collected in other ways, which underline the fact that this is just one more survey. True, it is more extensive than others (or will be) and it covers a wider age range and is therefore more representative of the whole population. But in essence this survey is unlikely to provide very different information from the British regional heart survey, ${ }^{7}$ other British surveys, ${ }^{8-11}$ or the World Health Organisation's MONICA project, ${ }^{12}$ which began in 1980. There have been enough similar surveys in other countries to provide a cross check on surveys done in the British population. ${ }^{1314}$ The important point is that the Health Survey for England contains nothing new, no big idea. Does $R \& D$ really mean Research is Dull?

Many clinical academics are totally disillusioned by the Universities Funding Council and its research ratings, which award brownie points mainly for laboratory based research. Clinicians are looking to the Department of Health's new research and development strategy to re-establish the importance of research programmes related to clinical work.

But if a thousand flowers are to bloom we must be wary of too much centralised direction. The track record of targeted research is not all that impressive: who remembers President Nixon's "Let's conquer cancer in the 70s"? A government dedicated in all other matters to the "supply side" must not equate "investigator led" with "inappropriate" research. It is clearly sensible to define priority areas and for fundholders to consider proposals for research from the academic supply side. It is not so obviously sensible for all research and development funding to be spent on projects defined to the last detail at the centre.

So far the research and development strategy seems to have been composed of talks about talks at the highest level followed by the production of glossy brochures, which may be educational but are a glimpse of the obvious to those in the field. What we need now are various clinical projects up and running, funded under the umbrella of research and develop- 